\title{
The Confusing World of Dry Powder Inhalers: It Is All About Inspiratory Pressures, Not Inspiratory Flow Rates
}

\author{
Andrew R. Clark, PhD, Jeffry G. Weers, PhD, ${ }^{2}$ and Rajiv Dhand, $\mathrm{MD}^{3}$
}

\begin{abstract}
Dry powder inhalers (DPIs) all have the ability to aerosolize dry powders, but they each offer different operating mechanisms and resistances to inhaled airflow. This variety has resulted in both clinician and patient confusion concerning DPI performance, use, and effectiveness. Particularly, there is a growing misconception that a single peak inspiratory flow rate (PIFR) can determine a patient's ability to use a DPI effectively, regardless of its design or airflow resistance. For this review article, we have sifted through the relevant literature concerning DPIs, inspiratory pressures, and inspiratory flow rates to provide a comprehensive and concise discussion and recommendations for DPI use. We ultimately clarify that the controlling parameter for DPI performance is not the PIFR but the negative pressure generated by the patient's inspiratory effort. A pressure drop $\sim \geq 1 \mathrm{kPa}\left(\sim 10 \mathrm{~cm} \mathrm{H}_{2} \mathrm{O}\right)$ with any DPI is a reasonable threshold above which a patient should receive an adequate lung dose. Overall, we explore the underlying factors controlling inspiratory pressures, flow rates and dispensing, and dispersion characteristics of the various DPIs to clarify that inspiratory pressures, not flow rates, limit and control a patient's ability to generate sufficient flow for effective DPI use.
\end{abstract}

Keywords: dispersion characteristics, dry powder inhalers, inspiratory flow rate, inspiratory pressure, respiratory review, In-check DIAL

\section{Introduction}

$\mathbf{I}$ N 1995, The Nobel Prize In Chemistry was awarded to Molina and Rowland for discovering that chlorofluorocarbons (CFCs), the propellants used in pressurized metered dose inhalers (pMDIs), depleted the Earth's protective ozone layer. ${ }^{(1)}$ This discovery led to the signing of the Montreal Protocol $^{(2)}$ and worldwide agreement to cease CFC manufacture. However, the Montreal Protocol and subsequent agreements presented a major dilemma for the pharmaceutical industry and clinicians. The continued availability of the pMDI, which since 1956 had been the preferred treatment modality for many respiratory diseases such as asthma and chronic obstructive pulmonary disease (COPD), was under threat. $^{(3)}$ The responses were many fold: replacement of
pMDI propellants, development of more efficient nebulizers, development of soft mist inhalers (SMIs), and the development of numerous novel dry powder inhalers (DPIs). ${ }^{(4,5)}$

Despite this huge effort, only one SMI has made it to the market, ${ }^{(6)}$ the utility of nebulizers remains in pediatric and elderly patients who have problems using other forms of inhalers, ${ }^{(7,8)}$ and the popularity of pMDIs remains unabated. ${ }^{(9)}$ While DPIs are more valuable in total sales value, the pMDI outweighs the DPI in total number of doses sold by a factor of four (Table 1). ${ }^{(9)}$ Nevertheless, the number of commercially available DPIs is ever-increasing. DPIs all have in common the ability to aerosolize dry powders. However, they differ from each other in the type of formulations, dose storage, and powder dispersion methods, and present the patient and clinician with a variety of operating

\footnotetext{
${ }^{1}$ Aerogen Pharma Corporation, San Mateo, California.

${ }^{2}$ Respira Therapeutics, Inc., Burlingame, California.

${ }^{3}$ Division of Pulmonary and Critical Care Medicine, Department of Medicine, University of Tennessee Graduate School of Medicine, Knoxville, Tennessee.

(C) Andrew R. Clark, et al., 2019. Published by Mary Ann Liebert, Inc. This Open Access article is distributed under the terms of the Creative Commons Attribution Noncommercial License (http://creativecommons.org/licenses/by-nc/4.0/), which permits any noncommercial use, distribution, and reproduction in any medium, provided the orginal author(s) and the source are credited.
} 
Table 1. Summary of Total Worldwide

Sales of Inhaled Products in 2014 as Reported By Stein AND Thiel Based ON IMS Data ${ }^{(9)}$

\begin{tabular}{lccc}
\hline & $\begin{array}{c}\text { Total sales } \\
\text { (billions } \$ \text { ) }\end{array}$ & $\begin{array}{c}\text { Total units } \\
\text { sold (millions) }\end{array}$ & $\begin{array}{c}\text { Total doses } \\
\text { sold } \text { (billions) }\end{array}$ \\
\hline Nebulizer & 5.07 & & \\
pMDI & 12.58 & 418 & 74.79 \\
DPI & 17.89 & 367 & 19.02 \\
All inhalable & 35.96 & & \\
$\quad$ forms & & & \\
\hline
\end{tabular}

IMS (Intercontinental Medical Statistics) Health; now IQVIA Inc. (Durham, NH). [MIDAS ${ }^{\circledR}$, January, 2016 (report of integrated global sales activity from over 70 countries).]

DPI, dry powder inhaler; pMDI, pressurized metered dose inhaler.

mechanisms and resistances to inhaled airflow. ${ }^{(10)}$ While in some respects necessity, as the mother of invention, has resulted in a much broader choice of inhalation products, it has also resulted in confusion about their performance, use, and effectiveness.

It is in this context that this article attempts to put the confusing world of DPIs into a clinical perspective. First, we review DPI technologies, their performance, and consequent implications for use. Second, we examine the ability of patients to generate the inspiratory pressure drops and inhaled flow rates needed to use various DPIs effectively. Next, we examine common misconceptions about peak in- spiratory flow rate (PIFR) and use of DPIs. Then, finally, we suggest a method for assessing a patient's ability to effectively operate a DPI in a clinical setting before the prescribing decision. A number of excellent review articles are available on the use and misuse of inhalers and the various errors patients make. ${ }^{(11,12)}$ Those aspects of inhaler use are not reviewed here. Rather, a patient's ability to generate minimally adequate flows through the various devices and how this influences the devices' clinical use are discussed.

\section{Materials and Methods}

\section{Search strategy and selection criteria}

References for this review were identified through searches of PubMed for articles published from January 1990 to November 2018 using the terms "inhaler," "dry powder inhaler," "dry powder inhaler and inspiratory flow rate," and "dry powder inhaler and inspiratory pressure." The authors also identified relevant articles published between 1990 and 2018 in their personal files. Articles resulting from these searches and relevant references cited in those articles were reviewed. Articles published in English were included.

\section{Results}

\section{DPls and formulations}

By definition, DPIs use "dry" powdered drug as the form of choice. The drug is usually formulated in one of three

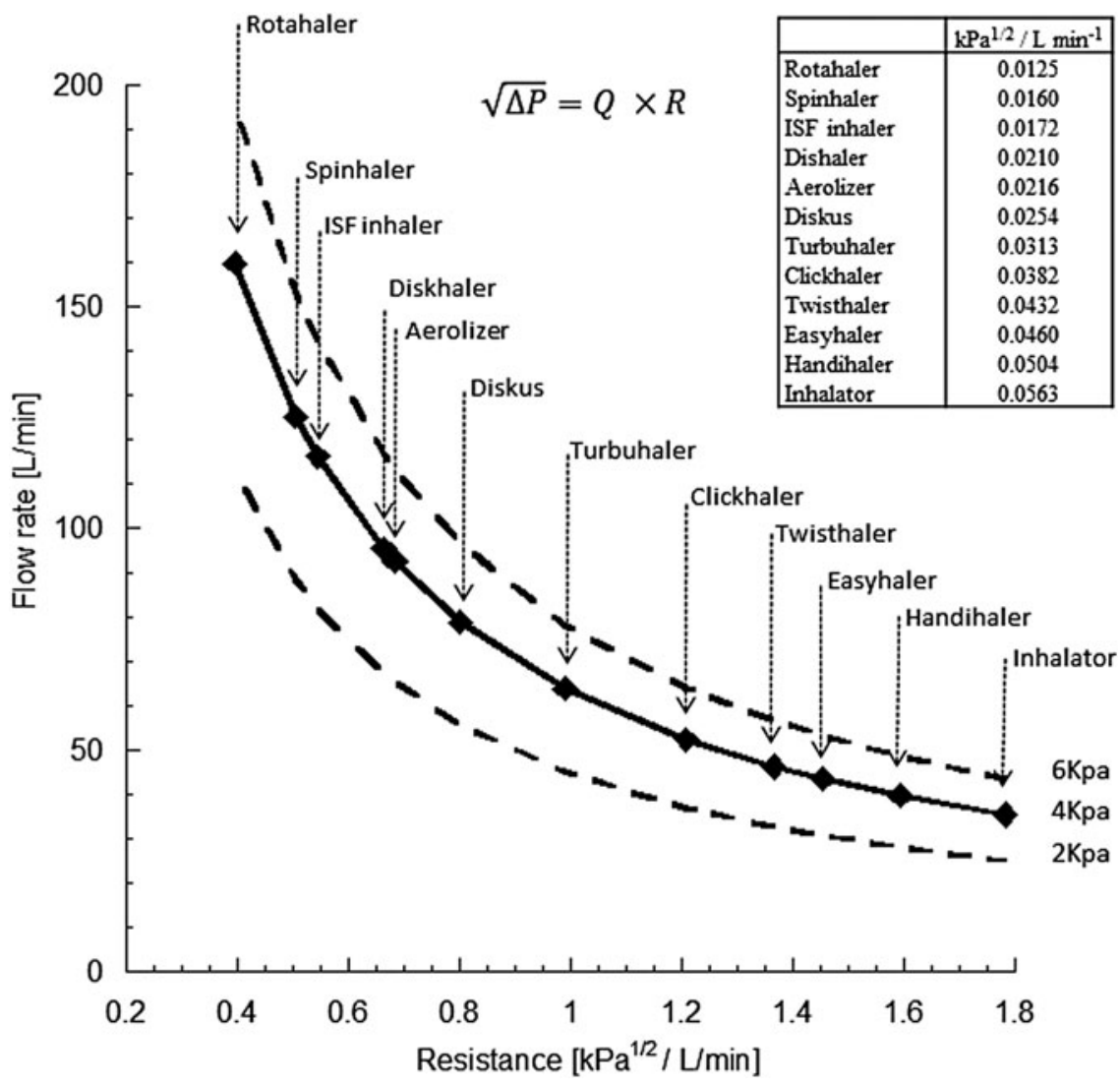

FIG. 1. Flow rate versus device resistance for several commercial DPIs. ${ }^{(21)}$ Points are at a $4 \mathrm{kPa}$ pressure drop. Lines are also presented for pressure drops of 2 and $6 \mathrm{kPa}$. Reproduced with permission from Bentham Science. DPI, dry powder inhaler. 
ways: as a fine micronized powder mixed with a large inactive "carrier" powder (usually lactose and referred to as lactose blends); as agglomerates or aggregates of micronized drug (referred to as spheronized particles); or as spraydried particles containing micronized or solubilized drug inside inert, rugous hydrophobic carrier materials (referred to as engineered particles). Lactose blends are by far the most common and have been in use since the 1960s. Products such as the Breo ${ }^{\circledR}$ and Anoro ${ }^{\circledR}$ Ellipta ${ }^{\circledR}$, the Advair ${ }^{\circledR}$ Diskus ${ }^{\circledR}$, the Foradil ${ }^{\circledR}$ Aerolizer $^{\circledR}$, and the Arcapta ${ }^{\circledR}$ Neohaler ${ }^{\circledR}$ all use lactose blends. Spheronized formulations are used in the Turbuhaler ${ }^{\circledR}$ line of products, including Pulmicort $^{\circledR}$ and Bricanyl ${ }^{\circledR}$, and in the Asmanex ${ }^{\circledR}$ Twisthaler $^{\circledR}$. The Tobi ${ }^{\circledR}$ Podhaler ${ }^{\mathrm{TM}}$ uses engineered particles.

While the inhaler designs differ, the varying formulations within them all require the patient to supply the energy to fluidize the powder, dispense it from the inhaler during inhalation, and disperse the formulation sufficiently well so that the drug component of the aerosol can penetrate and deposit in the lungs. ${ }^{(10,13,14)}$

To achieve this dispensing and dispersing, the formulations have been developed in conjunction with design elements of the inhalers, such as swirl chambers, grids, and orifices. These design elements, which differ between DPIs, present varying degrees of airflow resistance and result in DPIs with differing pressure drop/flow rate characteristics. In general, the flow rate though a DPI $(Q)$ is proportional to the square root of the pressure drop $(\Delta P)$ the patient develops across it, namely:

$$
\sqrt{\Delta P}=Q \times R
$$

The constant of proportionality is termed the device resistance $(R) .{ }^{(15)}$

Figure 1 presents flow rate resistance curves for a variety of inhalers, covering a range of pressure drops that are typically achievable by patients $(2-6 \mathrm{kPa}) .{ }^{(16)}$ Patients inhale faster through low-resistance devices and slower through high-resistance devices because the pressure drops they generate tend to be similar (Table 2). ${ }^{(17,18)}$

The interactions between these pressure drops, flow rates, and DPI formulations are complex. While larger pressure drops and higher flow rates through any individual inhaler (i.e., more effort made by the patient) generally result in better powder dispersion and finer particle aerosols with more drug reaching the lungs, this is not always the case. Figure 2 presents pressure drop "lung dose" plots for several commercial DPIs derived from data collated by Weers and Clark. ${ }^{(13,19-36)}$ Figure $2 \mathrm{~A}$ presents in vivo lung deposition data determined in scintigraphy and pharmacokinetic studies. ${ }^{(19-33)}$ Figure 2B presents in vitro data generated using upper airway casts (mouth and oropharynx) of adults. ${ }^{(34-36)}$

The data in these plots illustrate the two competing mechanisms: powder dispersion by the inhaler and upper airway filtering by the mouth and oropharynx. Powder dispersion generally improves as pressure drops and inhaled flow rates increase because the increased energy supply disperses the powder more effectively. At the same time, oropharyngeal filtering, which removes drug in the upper respiratory tract, increases with increasing flow rates due to inertial impaction. ${ }^{(37)}$ In most scenarios, powder dispersion "wins" and lung dose increases with increasing flow rate. Hence, the common understanding that patients should be

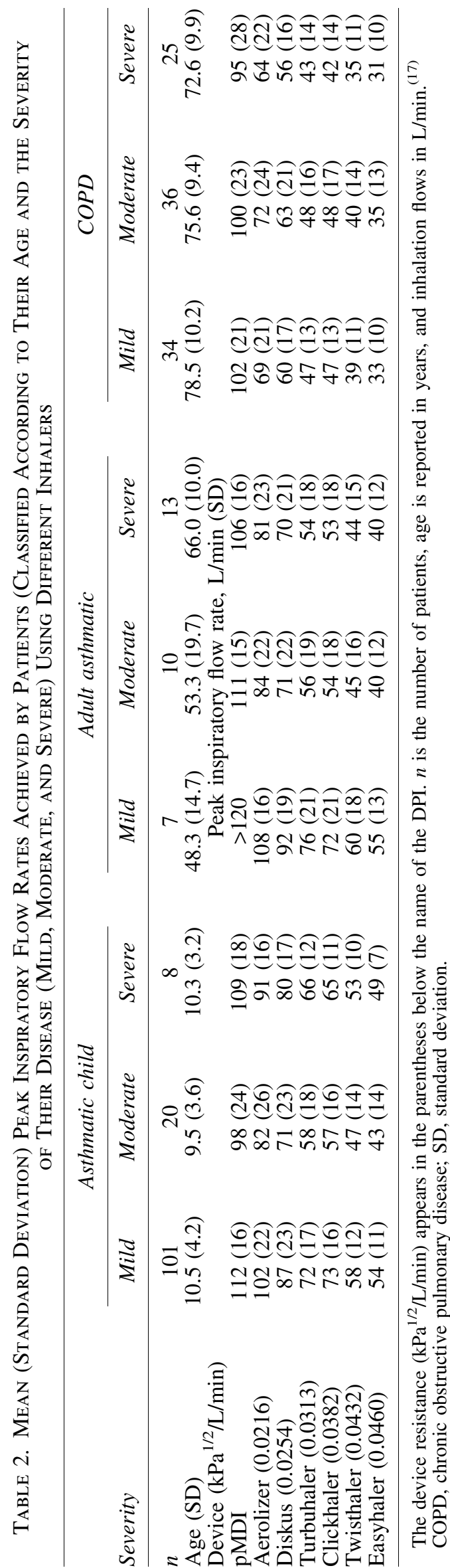



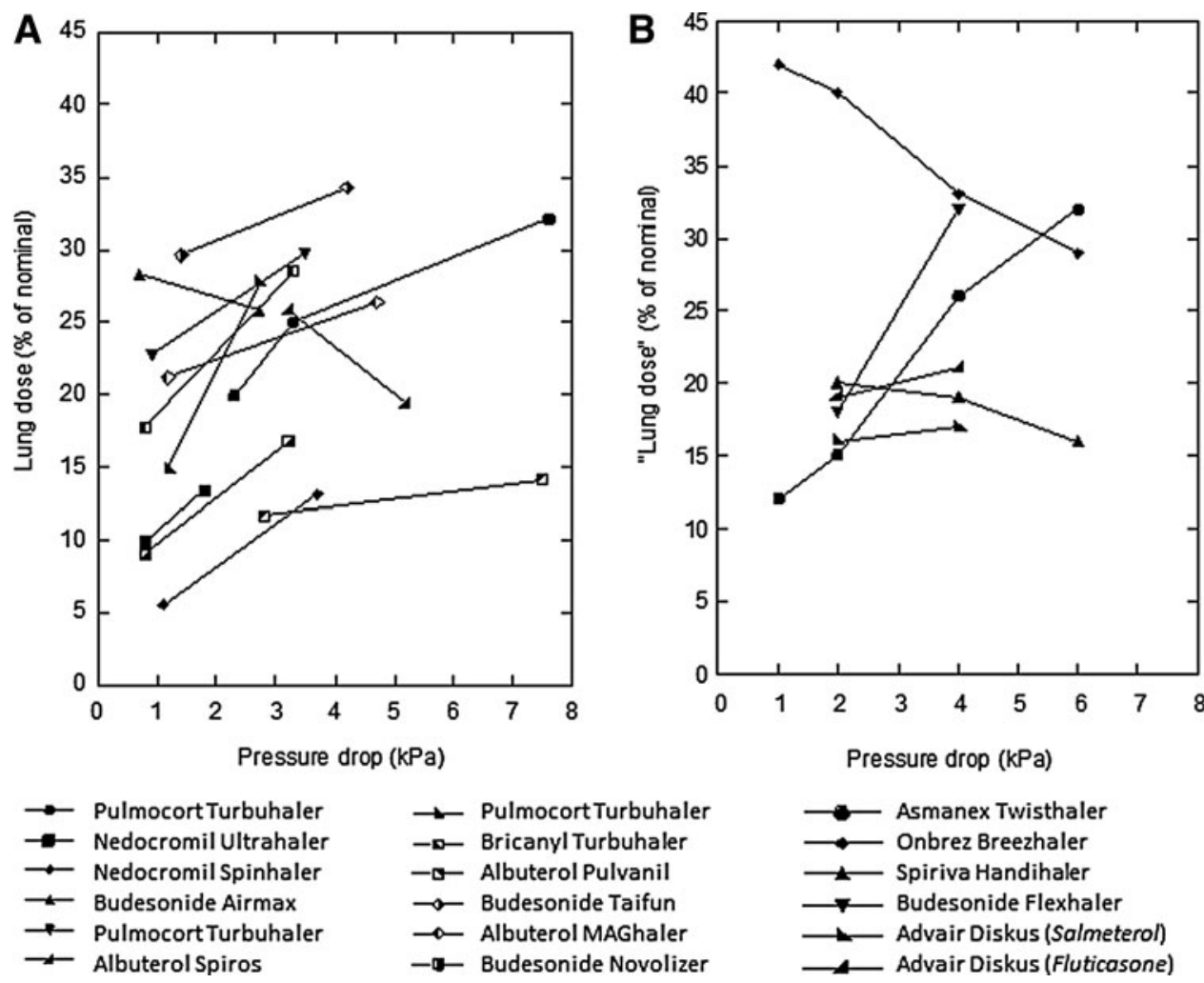

FIG. 2. Lung dose versus pressure drop for several commercial DPIs. ${ }^{(13)}$ (A) In vivo data determined using either gamma scintigraphy or pharmacokinetics. ${ }^{(19-33)}(\mathbf{B})$ In vitro data determined using cascade impactors or mouth/oropharyngeal models. ${ }^{(34-36)}$ encouraged to inhale forcefully, and at the highest pressure drop/flow rate they can attain, so as to ensure the greatest lung dose possible. ${ }^{(3)}$

However, there are exceptions to this rule where lung dose can decrease with increasing pressure drop/flow rates; that is, where oropharyngeal filtering increases more rapidly than powder dispersion. As shown in Figure 2, it would be advantageous to inhale at a more moderate flow rate when using the budesonide Airmax, the Onbrez Breezhaler, and Spiriva HandiHaler (the Albuterol Spiros also shows a decreasing lung dose with increasing flow rate, but this is because it is an active inhaler and does not rely on a patient's inspiration to disperse the powder. Hence, it delivers a constant size aerosol regardless of the patient inspiratory flow rate). Furthermore, as the inhalation flow increases, deposition in the central airways increases and distribution uniformity throughout the airways tends to decrease. ${ }^{(38)}$

\section{Patient physiology}

The resistance of all commercial DPIs is much larger than the resistance of the human airways, ${ }^{(39)}$ and hence, the achievable flow rate through a given DPI is limited by the maximum pressure drop (maximum inspiratory mouth pressure, or MIP) a patient can generate during inspiration and not by the resistance of the patients conducting airways. This pressure drop is dependent upon respiratory muscle strength and muscle tone, mainly varying with age and gender. ${ }^{(40)}$

This is why the literature suggests that age and gender are the only consistent correlates to inspiratory flows through
DPIs. To a lesser extent, airways disease can affect MIP. Airways disease can directly compromise respiratory muscle function, or it can increase the lung volume from which a patient begins an inhalation. The strength of the respiratory muscles decreases with lung inflation, with maximum muscle strength at residual volume and almost zero approaching total lung capacity when the respiratory muscles are fully extended. ${ }^{(41)}$ Thus, if a patient begins inhalation from a larger lung volume, they will naturally produce a lower mouth pressure.

Figure 3 presents a summary of MIP versus age and gender in healthy subjects. ${ }^{(39,42-46)}$ MIP increases from birth to around the mid-twenties and then declines toward old age. Although not necessarily true with some modern DPI formulations, ${ }^{(4)}$ this relationship drives the clinical observation that young children with asthma and elderly patients with COPD may lack the ability to generate sufficient flows (pressures) to correctly operate a DPI. ${ }^{(4)}$

\section{Effect of disease on inspiratory flow in DPIs}

The inspiratory flow achieved through a device is lower when the resistance of the device is higher. However, a low inhalation flow rate does not necessarily translate to inadequate powder deaggregation during patient use. Most patients with COPD are able to generate the inspiratory flows necessary for effective DPI use (Table 2), ${ }^{(1,48,49)}$ and as explained above, in general, peak inspiratory flows do not correlate with forced expiratory volume in 1 second $\%$ predicted or other pulmonary function parameters. ${ }^{(48-51)}$ 


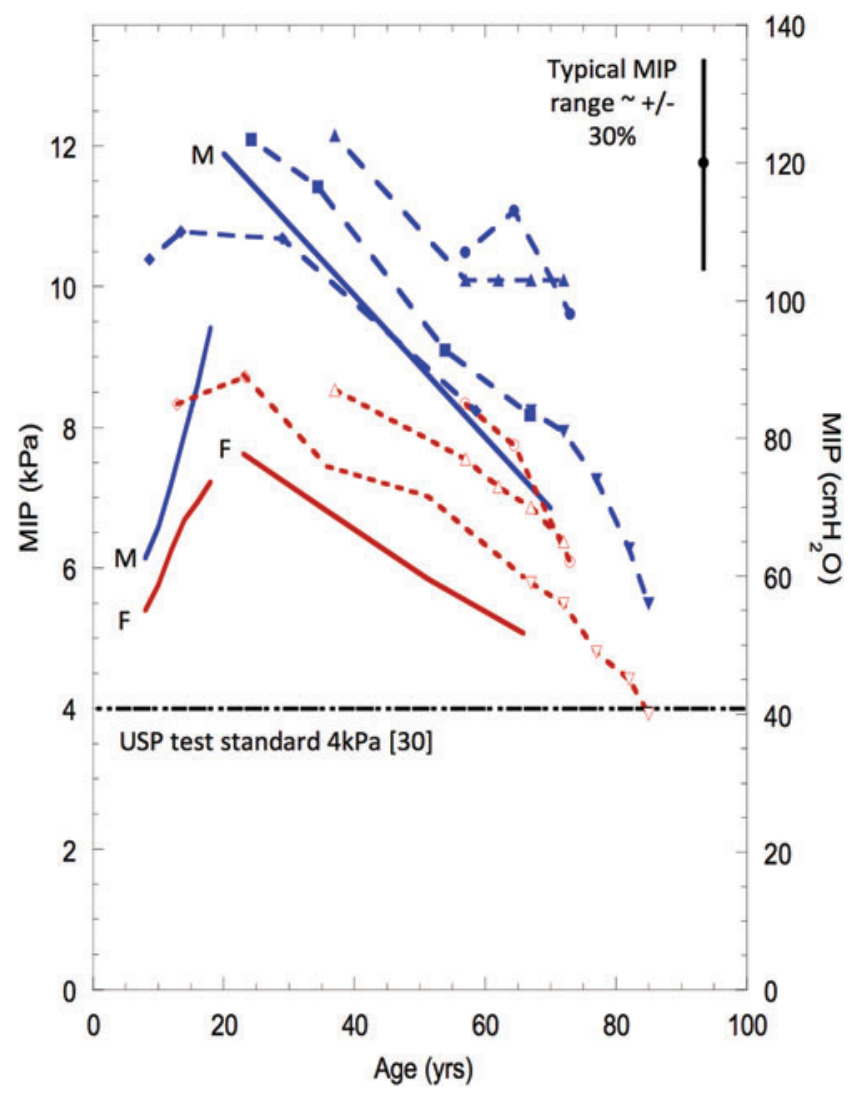

FIG. 3. MIP values as a function of age and sex. Solid lines represent predicted values using equations described by Wilson. ${ }^{(43)}$ These lines are marked as $\mathrm{M}$ and F. Long dashed lines are data from Ms, short dashed lines are data from Fs. Data derived from multiple publications ${ }^{(42-46)}$ and were summarized by Clark. ${ }^{(39)}$ Reproduced with permission from Bentham Science. F, female; M, male; MIP, maximum inspiratory mouth pressure. Color images are available online.

Figure 4 presents a summary of the average pressure drop attained through commercially available inhalers versus age for various patient groups. ${ }^{(39,43,52-63)}$ Pressure drop has been used in this figure as a way of uniformly presenting the data from the numerous studies since device pressure drop is the controlling parameter: the square root of the pressure drop divided by the device resistances defines the inhaled flow rate, not the other way around. It should be noted that the general form and slope of the pressure drops exhibit the same pattern as the MIP with age, presented in Figure 3.

\section{Common misconceptions about flow requirements for DPIs in clinical practice}

Reliable data on the flow rates below which a particular inhaler will not deliver an adequate therapeutic lung dose are generally lacking in the literature and drug product information leaflets. A glance at Figure 2 confirms why this is the case. DPIs do not "turn off" in a binary manner, but rather slowly lose their ability to deliver adequate lung doses as pressure drops and flow rates decrease. In addition to the physical reduction in lung dose with decreasing flow rate, there are also considerations around dose/response and where on the dose/response curve a minimum effective dose resides. It is therefore hard to define an exact minimum effective pressure drop/flow rate for a particular inhaler.

Table 3 presents reported minimum clinically effective pressure drops and flow rates for a number of commercially available inhalers as presented by Haidl et al. ${ }^{(64)}$ These data are a compilation of both in vivo and in vitro data reported in the literature and thus have a number of limitations. For example, some have been developed based on a therapeutic response while others are based on fine particle fractions measured in vitro. However, they do represent the best attempt so far at defining minimum flow rates and pressure drops for a patient to obtain a clinically adequate dose of medication from the various DPIs.

The important point to note from Table 3 is that, as would be expected, the minimum effective flow varies greatly across the range of devices. It should also be noted that a minimum pressure drop of around $1 \mathrm{kPa}$ is sufficient for any of the DPIs listed to deliver an adequate dose of medication. From a clinical perspective, this means that provided a patient can produce a pressure drop of at least $1 \mathrm{kPa}$ across an inhaler, he or she should receive an adequate dose of medication.

Hence, a cutoff around $1 \mathrm{kPa}$ would seem appropriate as a pressure drop where decrements in bronchodilation or clinical effect would be anticipated.

\section{Other parameters that can influence DPI performance}

The PIFR achieved while inhaling from a DPI has been emphasized. However, the time taken to achieve the PIFRthat is, rate of acceleration of the inspiratory flow-can also be important. Some powder inhalers deliver their dose rapidly following the start of an inhalation, and a major fraction of the dose can be delivered before the patient reaching PIFR. In these circumstances, the flow acceleration is obviously important. Figure 5 shows this effect. Two inhalation profiles building to the same PIFR, one with a fast acceleration and the other with slow acceleration, are superimposed on the time during which the dose leaves the two types of inhalers. The two examples are for a reservoir or multidose blister-type device and a capsule device. $^{(3)}$ Clearly, the dose can be delivered very early in the inspiration from some devices. Hence, the DPI instructions direct the patient to inhale rapidly from the start of inhalation and continue to inhale for as long as possible. This association of PIFR with the time of dose delivery from a DPI highlights the need to consider additional factors in the prescribing decision in addition to PIFR. ${ }^{65)}$

Adequate inhaled volumes to ensure delivery of a complete dose are a further consideration. ${ }^{(18)}$ In some situations, a number of inspirations may be needed to extract the powder from a particular DPI. This is particularly the case with high-dose inhalers such as the Tobi Podhaler (112 mg tobramycin/dose), which may require two inhalations to ensure patients adequately extract the full dose from each of the four capsules. ${ }^{(66)}$ However, it should be noted that the inhaled volume required to extract the dose from most inhalers is more than achievable by patients of all ages and disease severities.

\section{Discussion and Recommendations}

It is clear from the foregoing that the controlling factor in a patient's ability to operate a DPI effectively is the mouth 

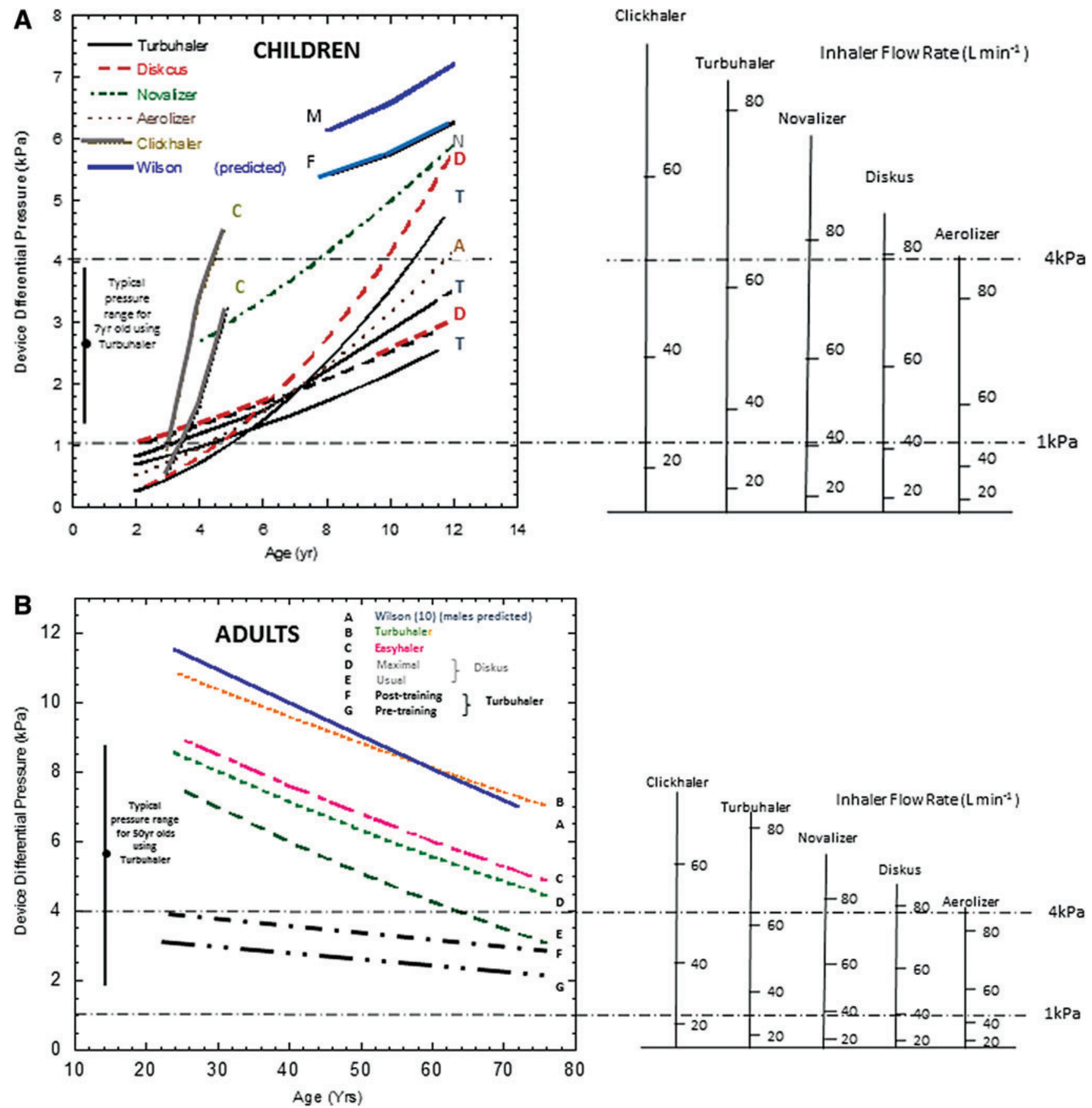

FIG. 4. Device pressure drops generated across five commercial DPIs with a nomogram showing the equivalent inhaler flow rates. ${ }^{(39,40)}$ (A) In children between 2 and 12 years of age. ${ }^{(52-60)}$ The letters next to the curves represent the first letter in the name of the device. The two lines labeled as $M$ and $F$ represent theoretical curves based on the equations of Wilson. ${ }^{(43)}$ (B) In adults 20-80 years of age. ${ }^{(61-63)}$ The slope of pressure drop versus age follows the same pattern as MIP with age (Fig. 3). ${ }^{(40)}$ The letters next to the curves represent lines as delineated in the legend within the graph. Reproduced with permission from Bentham Science. Color images are available online.

pressure he or she can generate and that this pressure is dependent primarily on the inspiratory muscle strength of the individual. Muscle strength increases with age, peaking at about age 25, after which it steadily declines. Males achieve greater mouth pressures than females, and the presence and severity of respiratory disease have only a minor impact. In clinical practice, patients rarely inhale with maximal effort, instead achieving pressure drops of about $40 \%-80 \%$ of their possible MIP. ${ }^{(39,40)}$
Most DPIs are passive, in the sense that they rely on the patient's inspiratory effort to fluidize and disperse the drug powder sufficiently well to enter and deposit in the lungs. Most inhalers contain design features (orifices, classifiers, etc.) that significantly increase particle velocities, particle impaction forces inside the inhaler, and powder dispersion. This can be true even at low inspiratory flow rates. ${ }^{(67)}$ For example, the average in vivo total lung dose achieved for tiotropium in the high-resistance HandiHaler ${ }^{\circledR}$, for 
Table 3. Literature Data on the Required Minimum Inspiratory Flow Rates to Use Several Dry Powder Inhalers ${ }^{(64)}$

\begin{tabular}{|c|c|c|c|c|c|}
\hline \multirow[b]{2}{*}{ Device } & \multirow{2}{*}{$\begin{array}{l}\text { Resistance } \\
\mathrm{R}\left(\mathrm{kPa}^{1 / 2} /\right. \\
\mathrm{L} / \mathrm{min})\end{array}$} & \multicolumn{2}{|c|}{$\begin{array}{l}\text { "Minimum" } \\
\text { effective }\end{array}$} & \multirow[b]{2}{*}{ Drug } & \multirow[b]{2}{*}{ In vitro observation } \\
\hline & & $\mathrm{Q}(L / \min )$ & $\Delta \mathrm{P}(k P a)$ & & \\
\hline \multicolumn{6}{|l|}{ In vitro ${ }^{\mathrm{a}}$} \\
\hline Twisthaler & 0.044 & $20<Q<28$ & 1.1 & Mometasone & Lower limit of acceptable in vitro performance \\
\hline HandiHaler & 0.051 & $23<Q<33$ & 1.2 & Tiotropium & Lower limit of in vitro performance \\
\hline HandiHaler & 0.051 & 28 & 1.2 & Tiotropium & $\begin{array}{l}\text { Fine particle dose reduced by } 30 \% \text { compared } \\
\text { to medium flow rates }(40 \mathrm{~L} / \mathrm{min})\end{array}$ \\
\hline \multicolumn{6}{|l|}{ In vivo ${ }^{\mathrm{b}}$} \\
\hline Diskus & 0.026 & 30 & 0.6 & Salmeterol & $\begin{array}{l}\mathrm{FEV}_{1} \text { shown to be equivalent at } 30 \mathrm{~L} / \mathrm{min} \\
\text { to that at } 60 \mathrm{~L} / \mathrm{min}\end{array}$ \\
\hline Turbuhaler & 0.036 & 31 & 1.2 & Terbutaline & $\begin{array}{l}\text { Maximal } \mathrm{FEV}_{1} \text { at } 1 \text { hour postdose shown } \\
\text { to be reduced at flow rates below } 31 \mathrm{~L} / \mathrm{min}\end{array}$ \\
\hline Turbuhaler & 0.034 & 36 & 1.4 & Budesonide & $\begin{array}{l}\text { Scintigraphically determined lung dose showed a } \\
50 \% \text { reduction when inhaled flow rate was } \\
\text { decreased from } 58 \text { to } 36 \mathrm{~L} / \mathrm{min}\end{array}$ \\
\hline Easyhaler & 0.041 & 30 & 1.4 & $\begin{array}{l}\text { Budesonide/ } \\
\text { formoterol }\end{array}$ & $\begin{array}{l}\text { AUC (area under the curve) of budesonide and } \\
\text { formoterol reduced by } 25 \% \text { and } 5 \% \text {, } \\
\text { respectively, when inhaled flow rate is reduced } \\
\text { from maximal effort flow rate }(82 \mathrm{~L} / \mathrm{min})\end{array}$ \\
\hline
\end{tabular}

${ }^{a}$ Data obtained in bench in vitro experiments.

${ }^{\mathrm{b}}$ Data obtained in clinical studies.

$\mathrm{FEV}_{1}$, forced expiratory volume in 1 second.

salmeterol in the medium-resistance Diskus, and for formoterol in the low-resistance Aerolizer, are all close to $20 \%$, despite the flow rates for the three inhalers at comparable inspiratory effort (pressure drops) being 39.2, 74.1, and $105.3 \mathrm{~L} / \mathrm{min}$. Thus, the inability to achieve an optimum flow rate with one DPI is not generalizable to other DPIs. Clearly, comparing inhalers using a single minimum flow across all inhalers is not only inadequate, it is misleading!

Current guidance is in the line with these observations, suggesting that passive DPIs are all flow-rate dependent and that young children and elderly patients are at risk of not being able to achieve the flow rates necessary to effectively

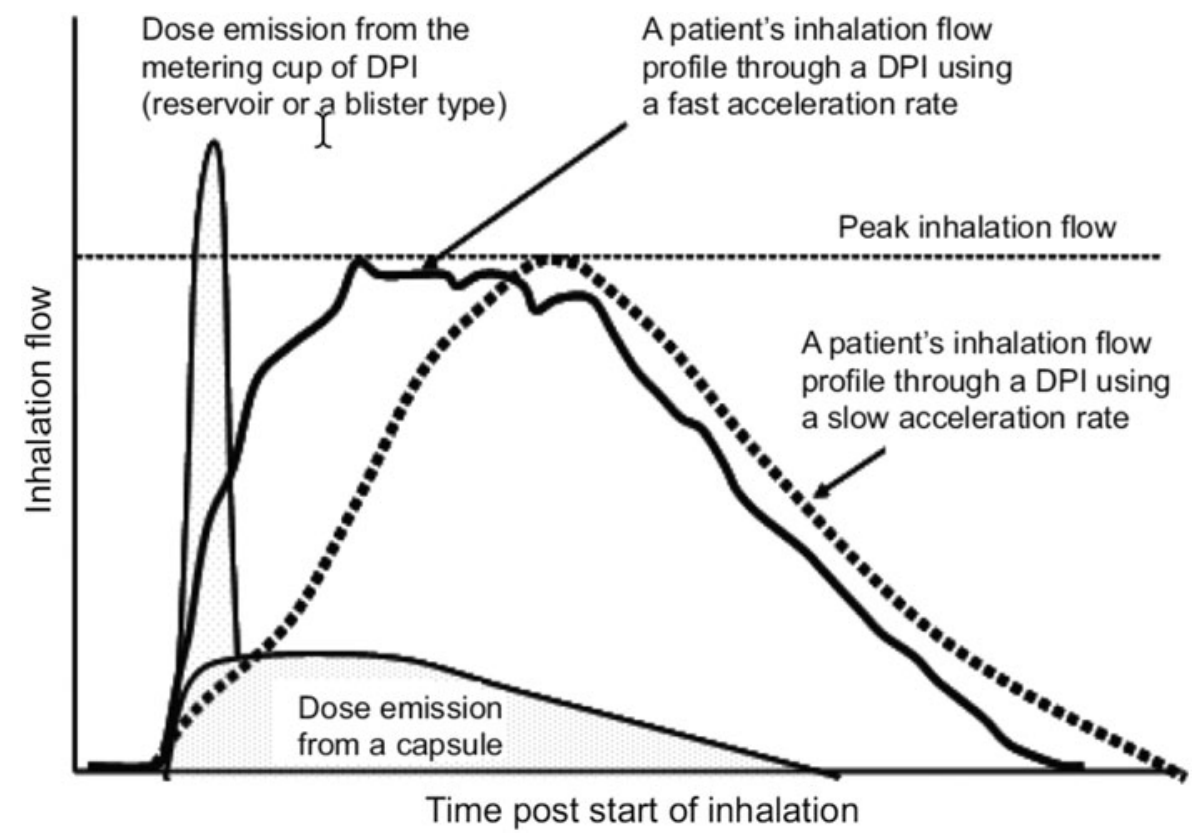

FIG. 5. The relationship between dose emission from a DPI and the patient's inhalation. ${ }^{(4)}$ Reproduced and modified from Laube et al. ${ }^{(4)}$ with permission from the publisher. 
disperse the powder. ${ }^{(4)}$ The underlying factors controlling inspiratory pressures, flow rates and dispensing, and dispersion characteristics of the various DPIs explain why this is the case.

While it is also clear then that some patients at the extremes of the population, with poor muscle strength, may not be able to achieve the inspiratory flow rates to utilize a given DPI, it remains unclear what that percentage might be. Having a test metric that would help inform a clinician of a patient's ability to use a particular inhaler product is undoubtedly an important unmet need. Any metric chosen as a means to delineate patients who can or cannot effectively use a given DPI has to be generalizable across inhalers of different designs and resistances. In this regard, a minimum PIFR is a very poor and misleading metric. Any metric that does not compare DPI devices of different resistances in a comparable manner is inherently flawed.

What then is the metric that would adequately assess a patient's ability to derive sufficient efficacy from a particular DPI? It should seem evident from the earlier discussion that this should be an assessment of mouth pressures and/or MIP, and that it is possible to ascribe a minimum pressure that is generalizable across most, if not all, inhaler designs.

The literature has examples where this approach would have been a useful metric. Loh et al. ${ }^{(68)}$ found significant decreases in time to readmission for patients with a PIFR on the In-Check DIAL $<60 \mathrm{~L} / \mathrm{min}$. According to the authors, this measurement was taken on the no resistance setting. If it is assumed that the no resistance setting has a resistance comparable with the Rotahaler, then the pressure drop for patients who cannot achieve a flow rate of $60 \mathrm{~L} / \mathrm{min}$ is $<0.5 \mathrm{kPa}$ (i.e., $<5 \mathrm{~cm} \mathrm{H}_{2} \mathrm{O}$ ). The data in Figure 2 show that this is an exceptionally low pressure drop, and patients who can only achieve such a low pressure drop should indeed be using an active inhaler device of some sort (i.e., a pMDI, SMI, or nebulizer). However, this is an uncommon observation in clinical practice. For example, $<5 \%$ of stable COPD patients in the study by Mahler et al. ${ }^{(50)}(n=213)$ had flow rates below $30 \mathrm{~L} / \mathrm{min}$ using the In-Check DIAL against the simulated resistance of a Diskus device $(\Delta P<0.6 \mathrm{kPa})$, and the study by Sharma et al. ${ }^{(69)}(n=268)$ observed similar results in patients admitted to the hospital for acute exacerbations of COPD on the day before discharge. The vast majority of patients hospitalized for acute exacerbations of COPD achieved peak inspiratory flows of $>30 \mathrm{~L} / \mathrm{min}$ using an In-Check DIAL against the simulated resistance of four commonly used DPIs. ${ }^{(69)}$ Azouz et al. ${ }^{(18)}$ found large variability in inhalation patterns among patients who used lowresistance devices. In contrast, they noted that Turbuhaler and Easyhaler (medium to high resistance) provided a more favorable set of inhalation characteristics in terms of formulation deaggregation and delivery of the emitted dose compared with low-resistance devices. In patients with COPD, fewer patients were unable to achieve adequate pressure drops when breathing through higher resistance devices compared with lower resistance DPIs (Fig. 6). Furthermore, according to data published by Pedersen et al., ${ }^{(70)}$ bronchodilation was independent of PIFR for the medium-resistance Turbuhaler device down to $\sim 0.8 \mathrm{kPa}$. In contrast, a significant fraction of pediatric patients received diminished bronchodilation with the low-resistance Rotahaler device at an equivalent pressure drop. The $0.8 \mathrm{kPa}$ pressure drop corresponds to $30 \mathrm{~L} / \mathrm{min}$ for the Turbuhaler and $72 \mathrm{~L} / \mathrm{min}$ for the Rotahaler. Numerous studies have
A

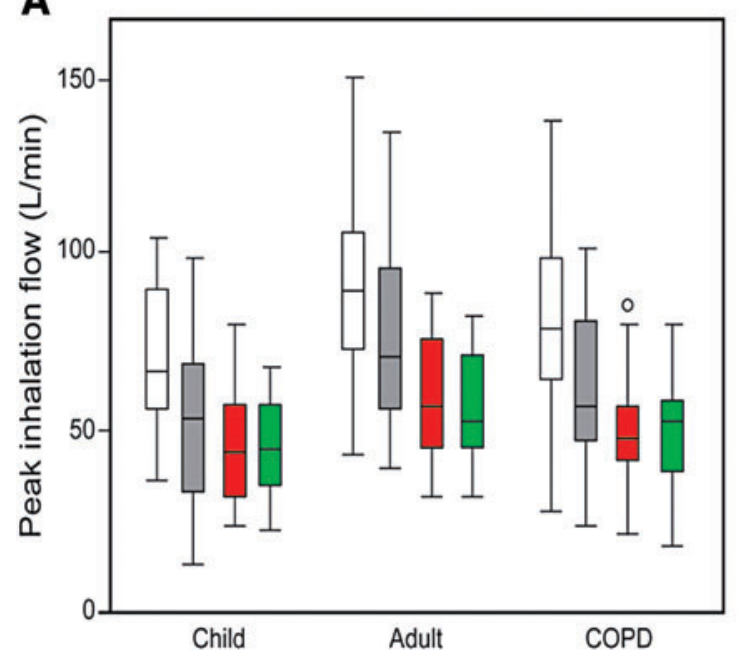

B

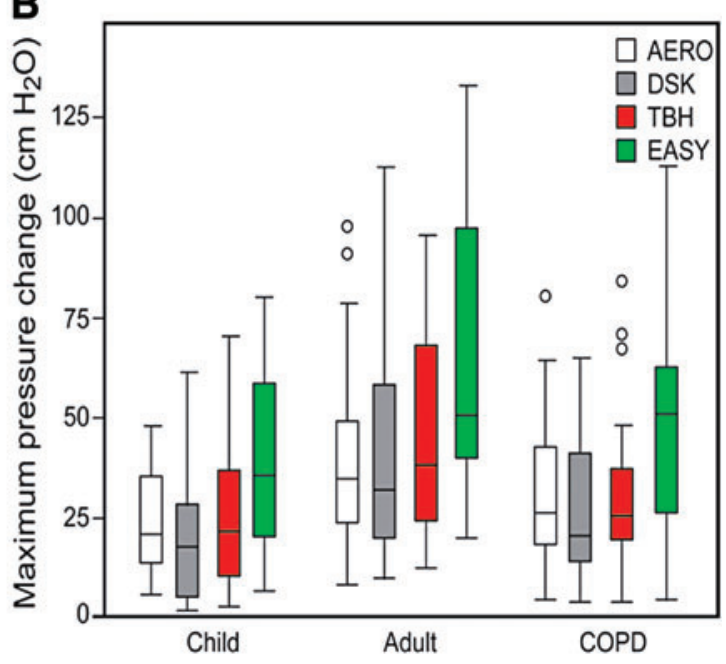

FIG. 6. Distribution of peak inhalation flow rates and pressures through various DPIs. (A) As expected, given the data in Figure 3, adults with asthma generate the most favorable inhalation maneuvers and children with asthma the weakest, with chronic obstructive pulmonary disease subjects performing slightly better than the children. Also as expected given the data in Figure 1, subjects generated higher flows through lower resistance devices (AERO, DSK) compared with higher resistance devices (TBH, EASY). (B) The equivalent distribution of pressure drops. In contrast to the peak inhalation flows (A), the pressure changes tended to be slightly greater for DPIs with a higher resistance (TBH, EASY) than those with a lower resistance (AERO, DSK). Boxes represent interquartile range with the median, and whiskers show the full range of the data, with outliers shown as circles. Reproduced from Azouz et al. ${ }^{(18)}$ with permission. AERO, Aerolizer; DSK, Diskus; EASY, Easyhaler; TBH, Turbuhaler. Color images are available online. 
demonstrated that virtually all geriatric patients, and pediatric patients older than the age of six, can achieve a PIFR greater than $30 \mathrm{~L} / \mathrm{min}$ with the Turbuhaler. ${ }^{(52,71)}$

The data in Table 2 suggest that a reasonable minimum pressure drop "cutoff" around $1 \mathrm{kPa}$ is appropriate as a pressure drop below which decrements in bronchodilation efficacy would be anticipated, and indeed where efficacy of any DPI product begins to be suspect.

From a practical perspective, use of the In-Check device is a popular way of assessing a patient's ability to generate flows through DPI devices of various resistances. However, it is not always used appropriately. If a constant flow rate is used as a metric, very different pressure drops will be achieved for different inhalers. For example, using the resistance data for different devices presented in Figure 1, a PIFR of $60 \mathrm{~L} / \mathrm{min}$ corresponds to the following pressure drops: $1.3 \mathrm{kPa}$ (Aerolizer), $1.6 \mathrm{kPa}$ (Diskhaler), $1.7 \mathrm{kPa}$ (Breezhaler), $2.6 \mathrm{kPa}$ (Diskus), $3.0 \mathrm{kPa}$ (Ellipta), $4.7 \mathrm{kPa}$ (Turbuhaler), and $9.4 \mathrm{kPa}$ (HandiHaler). Given the data in Table 2 and Figure 2, these sorts of pressure drops are unnecessary for the adequate use of these devices and are misleading in terms of a prescribing decision. Indeed, a suggestion that a $60 \mathrm{~L} / \mathrm{min}$ "cutoff", (70) (with the dial set to the specific resistance of the DPI) should be used to segregate patients who would benefit from a switch to an alternative active delivery system is clearly incorrect. For example, while the Diskus achieves a $60 \mathrm{~L} / \mathrm{min}$ flow rate at a $2.6 \mathrm{kPa}$ pressure drop, the flow rate that patients would achieve with the HandiHaler at this pressure drop is just $32 \mathrm{~L} / \mathrm{min}$. As stated above, both inhalers achieve comparable dose delivery to the lungs at a similar inspiratory effort (pressure drop), not at similar flow rates.

The more relevant and proper way to use the In-Check DIAL in such a circumstance is to convert the measured flow rates into pressure drops [using Eq. (1)] to enable comparison between inhalers of different resistances. Alternatively, one can test all subjects on the same setting (e.g., Aerolizer, with a $60 \mathrm{~L} / \mathrm{min}$ "cutoff" that corresponds to a $1.3 \mathrm{kPa}$ pressure drop) to assess the impediment they may have with respect to achievement of an adequate pressure drop through any DPI device. An alternative to the In-Check DIAL would be to choose a particular inhaler with known resistance, measure the PIFR through the inhaler, and then calculate whether the pressure drop is $<1 \mathrm{kPa}$.

Finally, it should be emphasized that many additional requirements are critical to the correct use of DPIs. Adequate training of patients to use their DPI is essential. While the minimum pressure drop cutoff approach proposed above assesses a patient's physical ability to use a DPI in terms of PIFR, other aspects associated with training and the ability to follow instruction leaflets impact the effectiveness of these products. ${ }^{(3)}$ Moreover, generation of an optimal pressure drop assures that the patient receives an adequate inhaled mass of the drug; however, the therapeutic efficacy of the drug is determined by deposition at its site of action in the lung. Therefore, several other factors, such as oropharyngeal deposition, drug dissolution, clearance mechanisms, and binding affinity, ultimately determine the therapeutic response to the drug.

In summary, inspiratory pressures, not flow rates, limit and control a patient's ability to generate sufficient flow for effective DPI use. Assessing patients' ability to generate a minimum pressure drop of around $1 \mathrm{kPa}$ across any resistance in the range of typical DPI device resistances should be an effective way of deciding if they are candidates for DPI use, or if they require an alternative active inhaler, such as a pMDI, pMDI and spacer, SMI, or a nebulizer.

\section{Author Disclosure Statement}

R.D. reports remuneration from GSK Pharmaceuticals, Boehringer-Ingelheim, and Astra-Zeneca Pharmaceuticals outside the submitted work. A.R.C. and J.G.W. have nothing to disclose.

\section{Funding Information}

The authors received no funding in support of this work.

\section{References}

1. Molina MJ, and Rowland FS: Stratospheric sink for chlorofluoromethanes: Chlorine atom-catalyzed destruction of ozone. Nature. 1974;249:810-812.

2. Ozone Secretariat: The Montreal Protocol on Substances That Deplete the Ozone Layer. United Nations Environment Programme, Nairobi, Kenya, 1987.

3. Thiel CG: From Susie's question to CFC free: An inventor's perspective on forty years of MDI development and regulation. Proc Respir Drug Deliv. 1996;1:115-124.

4. Laube BL, Janssens HM, de Jongh FH, Devadason SG, Dhand R, Diot P, Everard ML, Horvath I, Navalesi P, Voshaar T, Chrystyn H, European Respiratory Society, and International Society for Aerosols in Medicine: What the pulmonary specialist should know about the new inhalation therapies. Eur Respir J. 2011;37:1308-1331.

5. Dhand R, Cavanaugh T, and Skolnik N: Considerations for optimal inhaler device selection in chronic obstructive pulmonary disease. Cleve Clin J Med. 2018;85(Suppl.): S19-S27.

6. Newman S: Emerging inhaler technologies. In: Newman S (ed). Respiratory Drug Delivery: Essential Theory and Practice. Respiratory Drug Delivery Online; Richmond, VA. pp. 309-336, 2009.

7. O'Callaghan C, and Barry PW: The science of nebulized drug delivery. Thorax. 1997;52:S31-S44.

8. Dhand R, Dolovich M, Chipps B, Myers TR, Restrepo R, and Farrar JR: The role of nebulized therapy in the management of COPD: Evidence and recommendations. COPD. 2012;9:58-72.

9. Stein SW, and Thiel CG: The history of therapeutic aerosols: A chronological review. J Aerosol Med Pulm Drug Deliv. 2016;30:20-41.

10. Yang MY, Chan JG, and Chan HK: Pulmonary drug delivery by powder aerosols. J Control Release. 2014;193: 228-240.

11. Molimard M, Raherison C, Lignot S, Depont F, Abouelfath $\mathrm{A}$, and Moore N: Assessment of handling of inhaler devices in real life: An observational study in 3811 patients in primary care. J Aerosol Med. 2003;16249-254.

12. Wieshammer S, and Dreyhaupt J: Dry powder inhaler: Which factors determine the frequency of handling errors? Respiration. 2008;75:18-25.

13. Weers J, and Clark A: The impact of inspiratory flow rate on drug delivery to the lungs with dry powder inhalers. Pharm Res. 2017;34:507-528. 
14. Hoppentocht M, Hagedoorn P, Frijlink HW, and de Boer AH: Technological and practical challenges of dry powder inhalers and formulations. Adv Drug Deliv Rev. 2014;75: 18-31.

15. Clark AR, and Hollingworth AM: The relationship between powder inhaler resistance and peak inspiratory conditions in healthy volunteers-Implications for in vitro testing. J Aerosol Med. 1993;6:99-110.

16. Dhand R: Inhaled drug therapy 2016: The year in review. Respir Care. 2017;62:978-996.

17. Chrystyn H: Effects of device design on patient compliance: Comparing the same drug in different devices. RDD Europe 2009. 2009;1:105-106.

18. Azouz W, Chetcuti P, Hosker HS, Saralaya D, Stephenson $\mathrm{J}$, and Chrystyn $\mathrm{H}$ : The inhalation characteristics of patients when they use different dry powder inhalers. J Aerosol Med Pulm Drug Deliv. 2015;28:35-42.

19. Pitcairn G, Reader S, Pavia D, and Newman S. Deposition of corticosteroid aerosol in the human lung by Respimat soft mist inhaler compared to deposition by metered dose inhaler or by Turbuhaler dry powder inhaler. J Aerosol Med. 2005;18:264-272.

20. Newman SP, Hirst PH, and Pitcairn GR. Scintigraphic evaluation of lung deposition with a novel inhaler device. Curr Opin Pulm Med. 2001;7(Suppl. 1):S12-S14.

21. Pitcairn GR, Lim J, Hollingworth A, and Newman SP. Scintigraphic assessment of drug delivery from the Ultrahaler dry powder inhaler. J Aerosol Med. 1997;10:295-306.

22. Newman SP, Hollingworth A, and Clark AR. Effect of different modes of inhalation on drug delivery from a dry powder inhaler. Int J Pharm. 1994;102:127-132.

23. Duddu SP, Sisk SA, Walter YH, Tarara TE, Trimble K, Clark AR, Eldon M, Elton RC, Pickford M, Hirst PH, Newman SP, and Weers JG: Improved lung delivery from a passive dry powder inhaler using an engineered PulmoSphere $^{\mathrm{TM}}$ powder. Pharm Res. 2002;19:689-695.

24. Hirst PH, Newman SP, Clark DA, and Hertog MGL: Lung deposition of budesonide from the novel dry powder inhaler Airmax $^{\mathrm{TM}}$. Respir Med. 2002;96:389-396.

25. Borgström L, Bondesson E, Morén F, Trofast E, and Newman SP: Lung deposition of budesonide inhaled via Turbuhaler ${ }^{\circledR}$ : A comparison with terbutaline sulphate in normal subjects. Eur Respir J. 1994;7:69-73.

26. Hill M, Vaughan L, and Dolovich M: Dose targeting for dry powder inhalers. Proc Respir Drug Deliv V. 1996;1: 197-208.

27. Newman SP, Morén F, Trofast E, Talaee N, and Clarke SW: Terbutaline sulphate Turbuhaler: Effect of inhaled flow rate on drug deposition and efficacy. Int $\mathrm{J}$ Pharm. 1991;74:209-213.

28. Pitcairn G, Lunghetti G, Ventura P, and Newman S: A comparison of the lung deposition of salbutamol inhaled from a new dry powder inhaler, at two inhaled flow rates. Int J Pharm. 1994;102:11-18.

29. Olsson B, Borgström L, Asking L, and Bondesson E: Effect of inlet throat on the correlation between measured fine particle dose and lung deposition. Proc Respir Drug Deliv V. 1996;1:273-281.

30. Pitcairn GR, Lankinen T, Seppälä O-P, and Newman SP: Pulmonary drug delivery from the Taifun ${ }^{\circledR}$ dry powder inhaler is relatively independent of the patient's inspiratory effort. J Aerosol Med. 2000;13:97-104.

31. Newman S, Malik S, Hirst P, Pitcairn G, Heide A, Pabst J, Dinkelaker A, and Fleischer W: Lung deposition of sal- butamol in healthy human subjects from the MAGhaler ${ }^{\circledR}$ dry powder inhaler. Respir Med. 2002;96:1026-1032.

32. DeLong M, Wright J, Dawson M, Meyer T, Sommerer K, and Dunbar C: Dose delivery characteristics of the $\mathrm{AIR}^{\circledR}$ pulmonary delivery system over a range of inspiratory flow rates. J Aerosol Med. 2005;18:452-459.

33. Wildhaber JH, Devadason SG, Wilson JM, Roller C, Lagana T, Borgström L, and LeSouëf PN. Lung deposition of budesonide from Turbuhaler ${ }^{\circledR}$ in asthmatic children. Eur J Pediatr. 1998;157:1017-1022.

34. Ung KT, Rao N, Weers JG, Clark AR, and Chan H-K: In vitro assessment of dose delivery performance of dry powders for inhalation. Aerosol Sci Technol. 2014;48: 1099-1110.

35. Ung KT, and Chan H-K: Effects of ramp-up of inspired airflow on in vitro aerosol dose delivery performance of certain dry powder inhalers. Eur J Pharm Sci. 2016;84: 46-54.

36. Weers JG, Ung K, Le J, Rao N, Ament B, Axford G, Maltz D, Glusker M, and Chan L: Dose emission characteristics of placebo PulmoSphere ${ }^{\mathrm{TM}}$ particles are unaffected by a subject's inhalation maneuver. J Aerosol Med Pulm Drug Del. 2013;26:56-68.

37. Cheng YS: Aerosol deposition in the extrathoracic region. Aerosol Sci Technol. 2003;37:659-671.

38. Usmani OS, Biddiscombe MF, and Barnes PJ: Regional lung deposition and bronchodilator response as a function of beta-2 agonist particle size. Am J Respir Crit Care Med. 2005;172:1497-1504.

39. Clark AR: The role of inspiratory pressures in determining the flow rate through dry powder inhalers; a review. Curr Pharm Design. 2015;21:3973-3983.

40. Clark AR: Analyzing 20 years of clinical studies on inspiration through dry powder inhalers. Proc Respir Drug Deliv. 2016;1:99-107.

41. Cook CD, Mead J, and Orzalesi MM: Static volumepressure characteristics of the respiratory system during maximal efforts. J Appl Physiol. 1964;19:1016-1022.

42. Black LF, and Hyatt RE: Maximal respiratory pressures: Normal values and relationship to age and sex. Am Rev Respir Dis. 1969;99:696-702.

43. Wilson SH, Cooke NT, Edwards RHT, and Spiro SG: Predicted normal values of maximal respiratory pressures in Caucasian adults and children. Thorax. 1984;39:535-538.

44. Chen HI, and Kuo CS: Relationship between respiratory muscle function and age, sex, and other factors. J Appl Physiol. 1989;66:943-948.

45. McElvaney G, Blackie S, Morrison NJ, Wolcox PG, Fairbarn MS, and Pardy RL: Normal static respiratory pressures in the normal elderly. Am Rev Respir Dis. 1989;138:277281.

46. Enright PL, Kronmal RA, Manolio TA, Schenker MB, and Hyatt RE: Respiratory muscle strength in the elderly. Am J Respir Crit Care Med. 1994; 149:430-438.

47. Weers JG, Tarara TE, and Clark AR: Design of fine particles for pulmonary delivery. Expert Opin Drug Deliv. 2017;4:297-313.

48. Al-Showair RA, Tarsin WY, Assi KH, Pearson SB, and Chrystyn H: Can all patients with COPD use the correct inhalation flow with all inhalers and does training help? Respir Med. 2007;101:2395-2401.

49. Mahler DA, Waterman LA, and Gifford AH: Prevalence and COPD phenotype for a suboptimal peak inspiratory flow rate against the simulated resistance of the Diskus ${ }^{\circledR}$ 
dry powder inhaler. J Aerosol Med Pulm Drug Deliv. 2013; 26:174-179.

50. Mahler DA, Waterman LA, Ward J, and Gifford AH: Comparison of dry powder versus nebulized beta-agonist in patients with COPD who have suboptimal peak inspiratory flow rate. J Aerosol Med Pulm Drug Deliv. 2014;27:103-109.

51. Janssens W, VandenBrande P, Hardeman E, De Langhe E, Philips T, Troosters T, and Decramer M: Inspiratory flow rates at different levels of resistance in elderly COPD patients. Eur Respir J. 2008;31:78-83.

52. Pedersen S, Hansen OR, and Fugelsang G: Influence of inspiratory flow rate upon the effect of a Turbuhaler. Arch Dis Child. 1990;65:308-310.

53. Iqbal S M, Ritson S, Buck $\mathrm{H}$, Ellis $\mathrm{S}$, and Everard $\mathrm{M}$ : Majority of children aged 3 years and above can reliably inhale through the Clickhaler. Pediatr Pulmon. 2003; 36: 63-68.

54. Vogelborg C, Kremer H-J, Ellers-Lenz B, Engel M, Maus J, Conrad F, and Hermann R: Clinical evaluation of the peak inspiratory flow generated by asthmatic children through the Novolizer. Resp Med. 2004;98:924-931.

55. Amirav I, Newhouse MT, and Mansour Y: Measurement of peak inspiratory flow with In-check dial device to simulate low-resistance (Diskus) and high-resistance (Turbohaler) dry powder inhalers in children with asthma. Pediatr Pulmon. 2005;39:447-451.

56. Raissy HH, Davies L, Marshik P, and Kelly HW: Inspiratory flow through dry-powder inhalers (DPIs) in asthmatic children 2 to 12 years old. Pediatr Asthma Allergy Immunol. 2006;19:223-230.

57. Parry-Billings M, Birrell C, Oldham L, and O'Callaghan C: Inspiratory flow rate through a dry powder inhaler (Clickhaler $\left.^{\circledR}\right)$ in children with asthma. Pediatr Pulmon. 2003;35: 220-226.

58. Von Berg A, Kremer HJ, Ellers-Lenz B, Conrad F, Erb K, Maus J, and Hermann R: Peak inspiratory flow rates generated through the Novolizer ${ }^{\circledR}$ and Turbuhaler ${ }^{\circledR}$ dry powder inhaler devices by children with stable asthma. J Aerosol Med. 2007; 20:50-58.

59. Kamps AWA, Brand PLP, and Roodra RJ Variation of peak inspiratory flow through dry powder inhalers in children with stable and unstable asthma. Pediatr Pulmon. 2004;37: 65-70.

60. Tiddens H A, Geller DE, Challoner P, Speirs RJ, Kesser KC, Overbeek SE, Humble D, Shrewsbury SB, and Standaert TA: Effect of dry powder inhaler resistance on the inspiratory flow rates and volumes of cystic fibrosis patients age six years and older. J Aerosol Med. 2006;19:456-465.

61. Hawksworth GM, James L, and Chrystyn H: Characterization of inspiratory maneuver when asthmatics inhale through a Tubuhaler pre- and post-counseling in a community pharmacy. Respir Med. 2000; 94:501-504.

62. Baba K, Tanaka H, Nishimura M, Yokoe N, Takahashi D, Yagi T, Yamaguchi E, Maeda Y, Muto T, and Hasegawa T: Age-dependent deterioration of peak inspiratory flow with two kinds of dry powder corticosteroid inhalers (Diskus ${ }^{\circledR}$ and Turbuhaler ${ }^{\circledR}$ ) and relationships with asthma control. J Aerosol Med Pulm Drug Deliv. 2011;24:293-301.

63. Malmberg LP, Rytila P, Happonen P, and Haahtela T: Inspiratory flows through dry powder inhaler in chronic obstructive pulmonary disease: Age and gender rather than severity matters. Int J Chronic Obs Pulm Dis. 2010;5:257-262.

64. Haidl P, Heindl S, Siemon K, Bernacka M, and Cloes RM: Inhalation device requirements for patients' inhalation maneuvers. Respir Med. 2016;118:65-75.

65. Kamin WE, Genz T, Roeder S, Scheuch G, Trammer T, Juenemann R, and Cloes RM: Mass output and particle size distribution of glucocorticosteroids emitted from different inhalation devices depending on various inspiratory parameters. J Aerosol Med. 2002;15:65-73.

66. Haynes A, Geller D, Weers J, Ament B, Pavkov R, Malcolmson R, Debonnett L, Mastoridis P, Yadao A, and Heuerding S: Inhalation of tobramycin using simulated cystic fibrosis patient profiles. Pediatr Pulmonol. 2016;51: 1159-1167.

67. de Boer AH, Hagedoorn P, Hoppentocht M, Buttini F, Grasmeijer F, and Frijlink HW: Dry powder inhalation: Past, present and future. Expert Opin Drug Deliv. 2017;14: 499-512.

68. Loh CH, Peters SP, Lovings TM, and Ohar JA: Suboptimal inspiratory flow rates are associated with chronic obstructive pulmonary disease and all-cause readmissions. Ann Am Thorac Soc. 2017;14:1305-1311.

69. Sharma G, Mahler DA, Mayorga VM, Deering KL, Harshaw $\mathrm{O}$, and Ganapathy V: Prevalence of low peak inspiratory flow rate at discharge in patients hospitalized for COPD exacerbation. Chronic Obstr Pulm Dis. 2017;4:217-224.

70. Pedersen S: How to use a Rotahaler. Arch Dis Child. 1986; 61:11-14.

71. Mahler DA: Peak inspiratory flow rate as a criterion for dry powder inhaler use in chronic obstructive pulmonary disease. Ann Am Thorac Soc. 2017;14:1103-1107.

Received on July 3, 2019

in final form, September 11, 2019

Reviewed by:

Alex Duarte

Arzu Ari

Gerhard Puhlmann

Address correspondence to:

Rajiv Dhand, MD

Division of Pulmonary and Critical Care Medicine

Department of Medicine

University of Tennessee Graduate School of Medicine

1924 Alcoa Highway, U114

Knoxville, TN 37920

E-mail: rdhand@utmck.edu 